\title{
Horner syndrome: clinical perspectives
}

This article was published in the following Dove Press journal:

Eye and Brain

10 April 2015

Number of times this article has been viewed

\author{
Sivashakthi Kanagalingam ${ }^{1-3}$ \\ Neil R Miller ${ }^{1-3}$ \\ 'Department of Ophthalmology, \\ ${ }^{2}$ Department of Neurology, \\ ${ }^{3}$ Department of Neurosurgery, \\ The Johns Hopkins Hospital, \\ Baltimore, MD, USA
}

\begin{abstract}
Horner syndrome consists of unilateral ptosis, an ipsilateral miotic but normally reactive pupil, and in some cases, ipsilateral facial anhidrosis, all resulting from damage to the ipsilateral oculosympathetic pathway. Herein, we review the clinical signs and symptoms that can aid in the diagnosis and localization of a Horner syndrome as well as the causes of the condition. We emphasize that pharmacologic testing can confirm its presence and direct further testing and management.
\end{abstract}

Keywords: Horner syndrome, oculosympathoparesis, anisocoria, ptosis, anhidrosis

\section{Horner syndrome}

The disruption of sympathetic innervation to the eye gives rise to a constellation of symptoms consisting of miosis, ptosis, and anhidrosis. This syndrome was initially described in animals by the French physiologist Claude Bernard in $1854^{1}$ and subsequently in a soldier who sustained a gunshot injury to his neck. ${ }^{2}$ However, Swiss ophthalmologist Johann Friedrich Horner is largely credited to be the first to completely describe this syndrome in 1869 and to correctly attribute it to oculosympathetic paresis. ${ }^{3}$ (Figure 1)

\section{Localization}

\section{Central (first-order neuron) Horner syndrome}

First-order neurons are located in the posterolateral hypothalamus, and from there, sympathetic fibers pass through the lateral brain stem and extend to the ciliospinal center of Budge and Waller in the intermediolateral gray column of the spinal cord at C8-T1 (Figure 2). A central Horner syndrome caused by damage to any of these structures is ipsilateral to the lesion, is almost always unilateral, and often produces hemihypohidrosis of the entire body.

Lesions of the hypothalamus, such as tumor or hemorrhage, can cause an ipsilateral Horner syndrome with contralateral hemiparesis and contralateral hypesthesia. ${ }^{4,5}$ Lesions of the thalamus result in contralateral ataxic hemiparesis, contralateral hypoesthesia, vertical gaze paresis, and dysphasia. ${ }^{6}$ The combination of a unilateral Horner syndrome and a contralateral trochlear nerve paresis suggests a lesion of the dorsal mesencephalon. The lesion injures either the trochlear nucleus on the side of the Horner syndrome or the ipsilateral fascicle. ${ }^{7-10}$ Pontine lesions can produce a Horner syndrome associated with an ipsilateral abducens nerve paresis; however, bilateral abducens nerve palsies in this setting have also been reported. ${ }^{11}$
Correspondence: Neil R Miller

Wilmer Eye Institute, The Johns Hopkins Hospital, Woods 458, 600 North Wolfe

Street, Baltimore, MD 21287, USA

$\mathrm{Tel}+\mathrm{I} 4105023213$

$\mathrm{Fax}+\mathrm{I} 4105023214$

Email nrmiller@jhmi.edu 


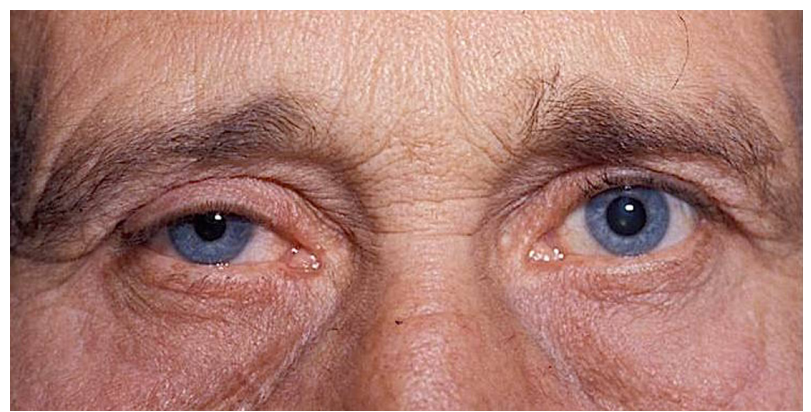

Figure I Right Horner syndrome in a 65-year-old man. Note right-sided upper lid ptosis, right miosis, and "upside-down" ptosis (ie, elevation) of right lower lid.

Lateral medullary infarction can cause several neurological deficits, including a central Horner syndrome. Among 33 consecutive patients with lateral medullary infarction, Horner syndrome was found in $91 \%$, ipsilateral ataxia in $85 \%$, and contralateral hypalgesia in $85 \% .{ }^{12}$ These features form the clinical triad known as the Wallenberg syndrome. Other neurological features, such as vertigo, dysphagia, nystagmus, and facial weakness, are less common. ${ }^{12}$ Wallenberg syndrome most often is caused by thrombotic occlusion of the ipsilateral vertebral artery, although isolated posterior inferior cerebellar artery disease also can produce this condition. ${ }^{13}$ In a series of 130 patients with lateral medullary infarction, the pathogenesis was large-vessel infarction in 50\%, arterial dissection in $15 \%$, small-vessel infarction in 13\%, and cardiac embolism in 5\%. ${ }^{14}$ Demyelinating disease of the medulla has also been reported to be the cause of Wallenberg syndrome. ${ }^{15}$

Lesions of the lower cervical or upper thoracic spinal cord can cause a central Horner syndrome. Occasionally, Horner syndrome may be the only neurological abnormality at presentation. Spinal cord lesions that may cause a central Horner syndrome include trauma, inflammatory or infectious myelitis, vascular malformation, demyelination, syrinx, syringomyelia, neoplasms, and infarction. ${ }^{16}$ Patients with the Brown-Séquard syndrome from trauma or cervical

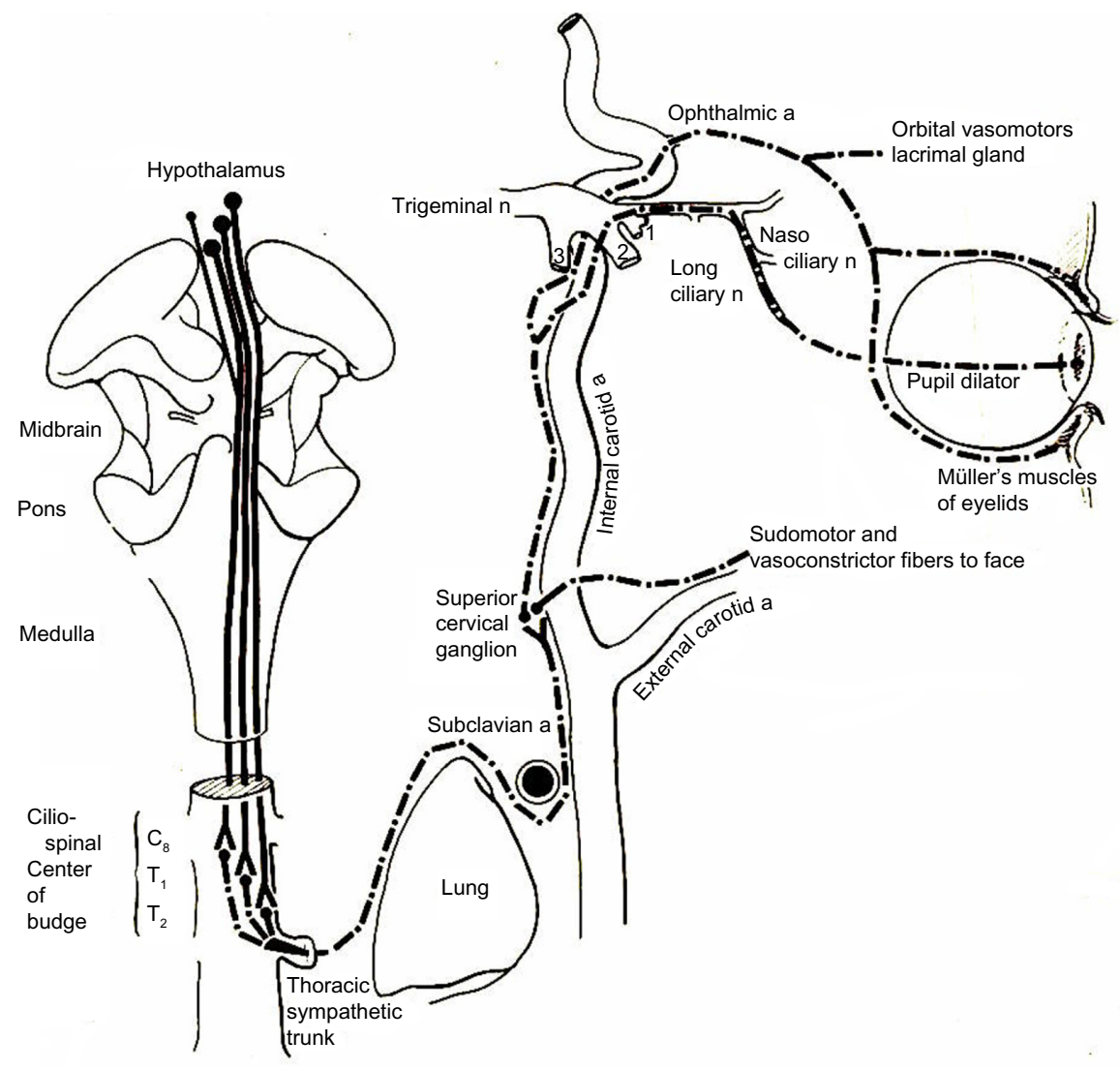

Figure 2 Drawing showing the anatomy of the oculosympathetic pathway.

Notes: Sympathetic fibers in the posterolateral hypothalamus pass through the lateral brain stem and to the ciliospinal center of Budge and Waller in the intermediolateral gray column of the spinal cord at C8-TI. Preganglionic sympathetic neurons exit from the ciliospinal center of Budge and Waller and pass across the pulmonary apex and ascend up the carotid sheath to the superior cervical ganglion. The postganglionic sympathetic neurons originate in the superior cervical ganglion and travel up the wall of the internal carotid artery. Once the fibers reach the cavernous sinus, they travel with the abducens nerve before joining the ophthalmic division of the trigeminal nerve and entering the orbit with its nasociliary branch. From here, they divide into two long ciliary nerves to reach the iris dilator muscle. Copyright $(9) 1978$ Wolters Kluwer. Reproduced with permission from. Glaser JS, editor. Neuro-ophthalmology. Ist ed. Hagerstown MD, USA: Harper \& Row; $1978 .{ }^{133}$

Abbreviations: a, artery; $\mathrm{n}$, nerve. 
disk herniation also have been noted to have a central Horner syndrome on the same side as the loss of light touch and motor function and contralateral to the side with the loss of temperature and pain sensation. ${ }^{17} \mathrm{~A}$ phenomenon termed alternating Horner syndrome (ie, alternating oculosympathetic deficit) can be seen in patients with cervical cord lesions and in some patients with systemic dysautonomias. ${ }^{18-20}$

\section{Preganglionic (second-order neuron) Horner syndrome}

The preganglionic sympathetic neurons exit from the ciliospinal center of Budge and Waller and pass across the pulmonary apex. They then ascend through the stellate ganglion and up the carotid sheath to synapse at the superior cervical ganglion, located at the level of the bifurcation of the common carotid artery and the angle of the jaw.

In a series of 450 patients with Horner syndrome, 270 $(65 \%)$ were found to have an identifiable cause. ${ }^{21}$ Of the patients with a detectible etiology, $13 \%$ had a central lesion, $44 \%$ had a preganglionic lesion, and $43 \%$ had a postganglionic lesion. In another large series, malignancy was the cause of about $25 \%$ of cases of preganglionic Horner syndrome. ${ }^{22}$ The most common tumors were lung and breast cancer. Horner syndrome usually presents long after the diagnosis of cancer has been established and only rarely has been part of the initial presentation. ${ }^{23}$

Apical lung lesions that spread locally to the region of the superior thoracic outlet can cause symptoms of ipsilateral shoulder pain, paresthesias along the medial arm, forearm, and fourth and fifth digits, weakness/atrophy of the hand muscles, and a preganglionic Horner syndrome. This combination of signs is called the Pancoast syndrome. The most common cause of Pancoast syndrome is non-small cell lung carcinoma; ${ }^{24,25}$ however, other primary apical tumors such as adenoid cystic carcinoma, hemangiopericytoma, and mesothelioma, have also been reported to cause this syndrome. ${ }^{26-29}$ Plasmacytoma, non-Hodgkin lymphoma, lymphomatoid granulomatosis, and metastases are other infrequent causes. ${ }^{30-33}$ A patient with a preganglionic Horner syndrome and ipsilateral shoulder pain should be investigated thoroughly for neoplastic involvement of the pulmonary apex, the pleural lining, and the brachial plexus, as this feature has been noted to be a reliable sign of underlying malignancies. $^{22}$

Pseudomonal and staphylococcal infections, tuberculosis, aspergillosis, and cryptococcosis have also been incriminated in the pathogenesis of Pancoast syndrome. ${ }^{34-38}$ Finally, sympathetic chain schwannomas, neuroectodermal tumor, vagal paraganglioma, and mediastinal tumors or cysts can also cause a preganglionic Horner syndrome. ${ }^{39-41}$

Injury to the brachial plexus or spinal roots, pneumothorax, fracture of the first rib, or neck hematoma are potential causes of a preganglionic Horner syndrome following trauma. In addition, the preganglionic sympathetic chains are vulnerable to iatrogenic injury. The varied anesthetic, radiologic, and surgical procedures that can produce an iatrogenic Horner syndrome include coronary artery bypass surgery, lung or mediastinal surgery, carotid endarterectomy, insertion of a pacemaker, epidural anesthesia, interpleural placement of chest tubes, internal jugular catheterization, and stenting of the internal carotid artery. ${ }^{42-47}$

Despite advances in neuroimaging and other diagnostic tests, as many as $28 \%$ of preganglionic Horner syndromes have no identifiable etiology. ${ }^{48}$

\section{Postganglionic (third-order neuron) Horner syndrome}

The postganglionic (third-order) sympathetic neurons originate in the superior cervical ganglion, travel in the wall of the internal carotid artery, and continue on to the cavernous sinus. Within the cavernous sinus, the fibers briefly travel with the abducens nerve before joining the ophthalmic division of the trigeminal nerve and entering the orbit with its nasociliary branch (Figure 3A and B). The sympathetic fibers in the nasociliary nerve divide into the two long ciliary nerves that travel with the lateral and medial suprachoroidal vascular bundles to reach the anterior segment of the eye and innervate the iris dilator muscle. ${ }^{49,50}$

Lesions of the internal carotid artery classically present with unilateral head and/or neck pain, focal cerebral ischemic symptoms, and a Horner syndrome. This form of Horner syndrome is often referred to as an incomplete Horner syndrome because it consists of ptosis and miosis but not anhidrosis. ${ }^{51}$ This is because the lesion affects the sympathetic fibers in the internal carotid plexus but spares the external carotid plexus that innervates the facial sweat glands. ${ }^{52,53}$ This painful Horner syndrome most often is caused by a traumatic or spontaneous dissection of the cervical internal carotid artery. In a large series of 146 patients with such lesions, a Horner syndrome was the most common finding, ${ }^{54}$ and in half of these cases was the initial and sole manifestation.

Internal carotid artery lesions other than dissections that are associated with a Horner syndrome include aneurysms, severe atherosclerosis, acute thrombosis, fibromuscular dysplasia, Ehler-Danlos syndrome, Marfan syndrome, and arteritis. ${ }^{55}$ In addition, mass lesions in the neck, such as 

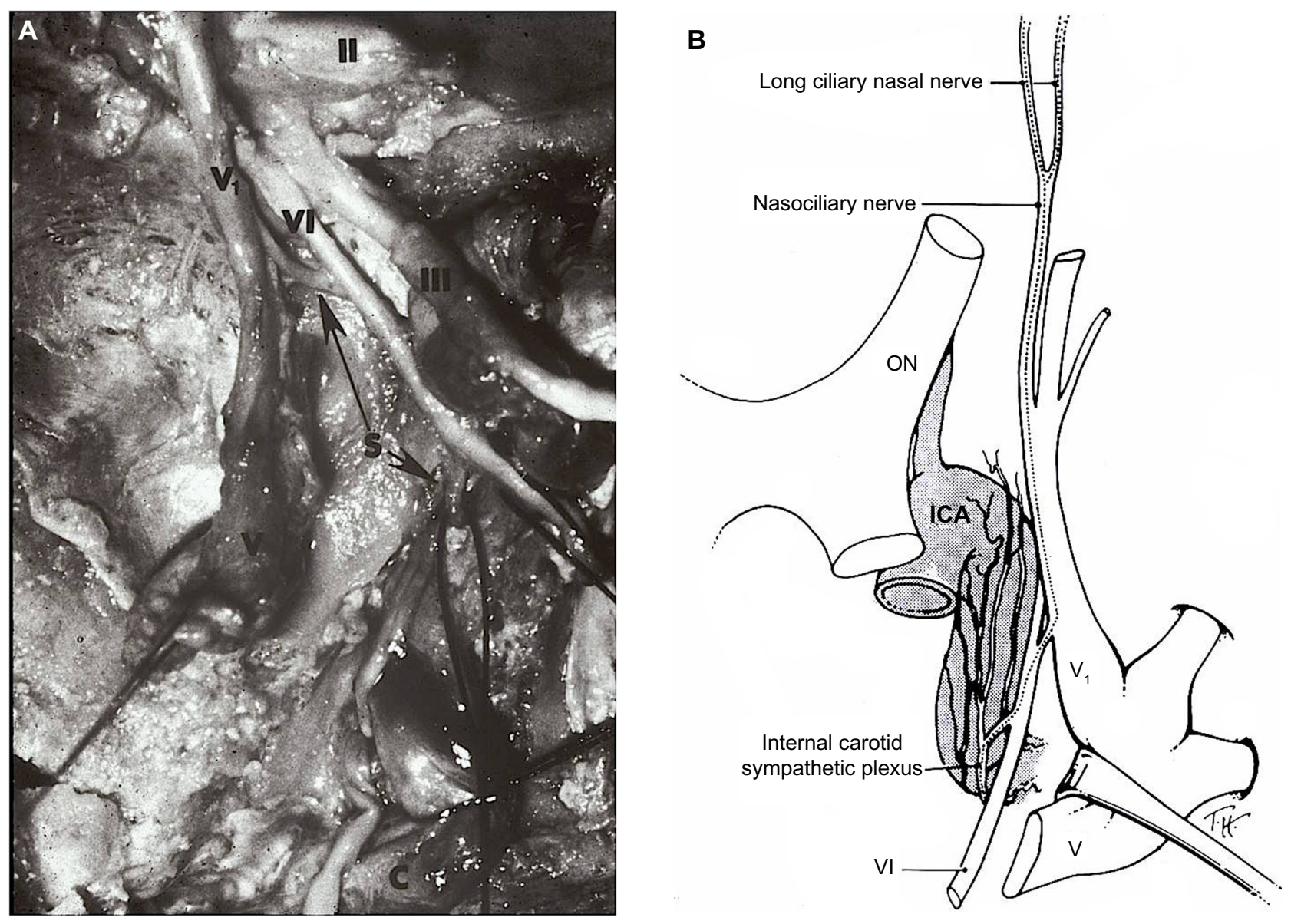

Figure 3 (A) Cadaver dissection showing oculosympathetic fibers $(\mathrm{S})$ attaching (lower arrow) to the abducens nerve (VI) within the cavernous sinus. After running with the nerve for a short distance, they separate from the nerve (upper arrow) and join with the first division of the trigeminal nerve $\left(V_{1}\right)$ to enter the orbit.

Notes: II, optic nerve; III, oculomotor nerve; V, trigeminal ganglion. Copyright ( 1978 Wiley-Liss, Inc. Adapted with permission from Parkinson D, Johnston J, Chaudhuri A. Sympathetic connections to the fifth and sixth cranial nerves. Anat Rec. Wiley Publishers. 1978;191:221-226. ${ }^{49}$ (B) Artist's drawing showing that the post-ganglionic oculosympathetic fibers briefly travel with the abducens nerve $(\mathrm{VI})$ before joining the ophthalmic division $\left(\mathrm{V}_{1}\right)$ of the trigeminal nerve. Thereafter, the sympathetic fibers enter the orbit with its nasociliary branch. Copyright (C) 2005, Lippincott Williams. Adapted with permission from Kardon R. Anatomy and physiology of the autonomic nervous system. In: Miller NR, Biousse V, Kerrison JB, editors. Walsh and Hoyt's Clinical Neuro-Ophthalmology. 6th ed. Baltimore, MD, USA: Lippincott-Williams \& Wilkins; 2005. ${ }^{134}$ Abbreviations: ON, optic nerve; ICA, internal carotid artery.

tumors, inflammatory masses, enlarged lymph nodes, and ectatic jugular veins, can compress the carotid sympathetic neurons, resulting in a Horner syndrome..$^{5,57}$

Damage to the superior cervical ganglion can cause a postganglionic Horner syndrome as the ganglion lies about $1.5 \mathrm{~cm}$ behind the palatine tonsil and can be damaged by traumatic penetrating intraoral injury or even procedures such as tonsillectomies, intraoral surgery, and peritonsillar injections. ${ }^{58,59}$ Skull base lesions can cause a postganglionic Horner syndrome that typically is associated with a variety of cranial nerve deficits. A middle fossa mass encroaching on Meckel's cave and on the internal carotid artery at the foramen lacerum can produce a Horner syndrome associated with trigeminal pain or sensory loss. A basal skull fracture involving the petrous bone can cause a Horner syndrome with an ipsilateral abduction deficit, facial palsy, and sensorineural hearing loss. ${ }^{60}$ Any lesion in the cavernous sinus may produce a postganglionic Horner syndrome in conjunction with one or more ocular motor nerves. The presence of an abducens palsy and a postganglionic Horner syndrome is highly suggestive of a lesion in the posterior cavernous sinus. ${ }^{61-65}$

Cluster headaches are severe lancinating unilateral headaches characterized by ipsilateral tearing, nasal stuffiness, conjunctival injection, and ptosis. A transient postganglionic Horner syndrome can be seen in 5\%-22\% of these patients, and permanent oculosympathetic paresis has been reported in some patients who experience repeated attacks. ${ }^{66,67}$ Raeder paratrigeminal neuralgia, a painful postganglionic Horner syndrome accompanied by ipsilateral trigeminal neuralgia, is associated with lesions in the middle cranial fossa medial to the trigeminal ganglion. ${ }^{68-70}$ 


\section{Horner syndrome in children}

The causes of Horner syndrome in children are usually classified as congenital or acquired (Figure 4). In addition to iris heterochromia, infants with Horner syndrome can demonstrate contralateral hemifacial flushing and ipsilateral hypohidrosis, called Harlequin syndrome. ${ }^{71}$ Congenital Horner syndrome is usually caused by birth trauma. ${ }^{71}$ In these cases, a history of delivery using forceps, vacuum extraction, shoulder dystocia, fetal rotation, and/or limb manipulation can usually be elicited. Concomitant brachial plexus injury is sometimes identified. ${ }^{71,72}$ Other etiologies include congenital tumors, postviral damage, and internal carotid artery agenesis, hypoplasia, and fibromuscular dysplasia. ${ }^{73-76}$

In a large study of 73 pediatric patients, $42 \%$ were noted to be congenital in nature, and $42 \%$ were acquired after a surgical procedure involving the thorax, neck, or central nervous system. ${ }^{71}$ Of the other $15 \%$ of acquired Horner syndromes, the etiologies included spinal cord tumors, neuroblastoma, rhabdomyosarcoma, brachial plexus trauma, intrathoracic aneurysm, embryonal cell carcinoma, and brain stem vascular malformations. . $^{71,77}$

Neuroblastoma is the most common occult malignancy associated with Horner syndrome, with an incidence of one in 7,000 children younger than the age of 5 years. ${ }^{78,79}$ Early detection of neuroblastoma is crucial as the prognosis for survival declines if the diagnosis is made after the age of 1 year. ${ }^{80,81}$ Hence, in a child with Horner syndrome in whom there is no clear history of surgery or birth trauma, a careful physical examination combined with urinary catecholamine testing and magnetic resonance imaging of the brain, neck, and chest is recommended. ${ }^{82}$ Using this principle, Jeffery et al found that $55 \%$ of children with an acquired Horner syndrome had a potentially fatal underlying disease, ${ }^{71}$ and Mahoney et al identified an underlying mass lesion in 21\% of their patients. ${ }^{82}$ Nevertheless, it should be noted that a significant number of pediatric Horner syndromes are idiopathic. George et al found no etiology in 16 of $23(70 \%)$ infants with Horner syndrome identified in the 1st year of

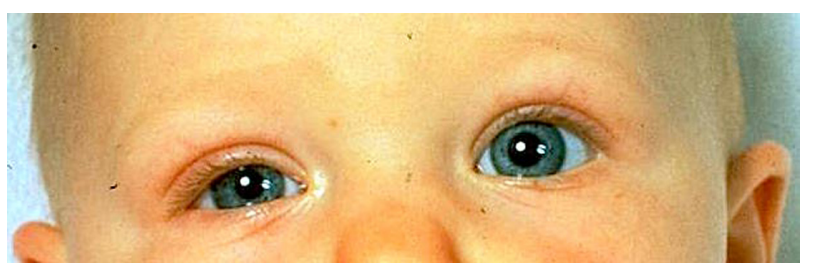

Figure 4 Infant with right Horner syndrome, demonstrating ipsilateral upper lid ptosis, "upside-down" ptosis of the lower lid, and anisocoria, with the right pupil smaller than the left. Both pupils reacted briskly to light stimulation. life, ${ }^{83}$ and Smith et al could not identify an etiology in $35 \%$ of children with a Horner syndrome who were followed for a mean period of 5 years. ${ }^{84}$

\section{Clinical features \\ Ptosis}

The ipsilateral upper eyelid appears slightly drooped due to paresis of the Müller muscle, a sympathetically innervated smooth muscle that also functions as an upper eyelid retractor $^{85,86}$ and is responsible for about $2 \mathrm{~mm}$ of upper eyelid elevation. ${ }^{87-89}$ Nonetheless, this ptosis may be subtle, variable, and go unnoticed. In addition, one study noted that in $12 \%$ of patients with Horner syndrome, the ptosis was in fact absent ${ }^{21}$ (Figure 1).

The smooth muscle fibers of the lower eyelid retractors also lose their sympathetic supply in patients with Horner syndrome and, thus, the lower eyelid appears slightly elevated. This appearance has been termed "upside-down ptosis" or "reverse ptosis". The combination of the upper eyelid ptosis and the lower eyelid elevation narrows the palpebral fissure, giving rise to an apparent enophthalmos. Several authors have since proven that this apparent enophthalmos is not of measurable significance, and hence is not true enophthalmos. ${ }^{90-92}$

\section{Pupillary signs}

Oculosympathetic paresis results in weakness of the iris dilator muscle on the affected side. The unopposed parasympathetic action of the iris constrictor muscle produces a smaller ipsilateral pupil. The resulting anisocoria is most apparent in darkness and may, in fact, be overlooked if the patient is evaluated in bright light. ${ }^{48}$

Several factors influence the degree of anisocoria in patients with Horner syndrome. For example, when a patient is fatigued or drowsy, the size of the pupils and the degree of anisocoria diminish as the hypothalamic sympathetic outflow to both eyes subsides and uninhibited parasympathetic outflow augments. The actual degree of anisocoria in Horner syndrome thus varies with the resting size of the pupils, the patient's alertness, the patient's fixation at distance and at near, the brightness of the examiner's light, the completeness of the injury, and the concentration of circulating adrenergic substances in the blood.

Paresis of the iris dilator muscle also impairs pupillary movement during dilation, termed dilation lag. Dilation lag can be seen clinically by illuminating the patient's eyes tangentially from below with a hand-held flashlight and then abruptly 
turning the room lights out. The normal pupil will immediately dilate, but the Horner pupil begins to dilate several seconds later. The difference in anisocoria is greatest after 4-5 seconds in the darkness. Thereafter, the Horner pupil slowly dilates from decreasing parasympathetic tone and eventually catches up in size to the normal pupil. Thus, if both pupils are observed simultaneously for 15-20 seconds after turning off the room light, one sees an initial increase in the degree of anisocoria, followed by decreasing anisocoria. Continuous recording pupillography has demonstrated that anisocoria is more marked at 4-5 seconds in darkness than it is at $10-12$ seconds. ${ }^{93}$ Taking photographs in darkness at 5 seconds and again at 15 seconds can reveal decreasing anisocoria in the later phase of dilation. ${ }^{94}$ Videography with infrared illumination can also demonstrate this phenomenon. ${ }^{95}$ Others have reported that a single measurement of anisocoria taken within the first 5 seconds of darkness is adequate for identifying dilation lag. One study reported that $0.6 \mathrm{~mm}$ or more at 4 seconds was $82 \%$ sensitive for diagnosing a unilateral Horner syndrome. ${ }^{96}$ Using binocular infrared video pupillometry with continuous recording of pupil diameters, Smith and Smith found that after a light flash, a delay in the time needed to recover three quarters of the baseline pupil size had a 70\% sensitivity and $95 \%$ specificity in detecting unilateral Horner syndrome. ${ }^{97}$ These investigators also found this method to be useful in detecting cases of bilateral Horner syndrome..$^{97}$ However, using this technology, Crippa et al noted that dilation lag is only intermittently present in patients with Horner syndrome, ${ }^{98}$ being present in $53 \%$ at the first determination and in $87 \%$ at some point during four determinations. They concluded that although dilation lag is a notable characteristic of Horner syndrome, it may not always be evident. Thus, a diagnosis of Horner syndrome should not eliminated in the absence of a demonstrable dilation lag of the smaller pupil.

\section{Iris hypochromia}

Sympathetic innervation is thought to be required for the formation of melanin by stromal melanocytes. ${ }^{72}$ Interruption of the sympathetic supply can lead to iris hypochromia on the affected side. This is a typical feature of congenital Horner syndrome. It is also occasionally seen in patients with a long-standing, acquired Horner syndrome, but never in patients with an acute or recently acquired Horner syndrome. ${ }^{99}$

\section{Accommodation}

A few authors have noted that patients with Horner syndrome can experience an increase in accommodative amplitude on the ipsilateral side. ${ }^{100,101}$

\section{Anhidrosis}

Characteristic vasomotor and sudomotor changes of the facial skin can occur on the affected side in some patients with Horner syndrome. Immediately following sympathetic denervation, the temperature of the skin rises on the side of the lesion because of loss of vasomotor control and consequent dilation of blood vessels. Additionally, there may be facial flushing, conjunctival hyperemia, epiphora, and nasal stuffiness in the acute stage. ${ }^{93,102,103}$ Some time after the injury, the skin of the ipsilateral face and neck may have a lower temperature and may be paler than that of the normal side. This occurs from supersensitivity of the denervated blood vessels to circulating adrenergic substances, with resultant vasoconstriction. ${ }^{100}$ However, in modern temperature-controlled spaces, patients with Horner syndrome rarely complain of disturbances of sweating or asymmetric facial flushing.

Paradoxical unilateral sweating with flushing of the face, neck, shoulder, and arm can be a late development in patients with a surgically induced Horner syndrome following cervical sympathectomy. Some axons in the vagus nerve normally pass into the superior cervical ganglion. These parasympathetic axons can establish, by collateral sprouting, anomalous vagal connections with postganglionic sympathetic neurons to the head and neck. ${ }^{104}$

\section{Diagnosis}

The diagnosis of Horner syndrome should be considered in any patient with anisocoria associated with what appears to be normal pupillary constriction to light in both the larger and smaller pupil. The presence of dilation lag of the smaller pupil, when present, is also helpful in making the diagnosis. Patients in whom a Horner syndrome is suspected should be evaluated for evidence of cranial nerve dysfunction, particularly an ipsilateral abducens nerve paresis that may indicate a lesion of the cavernous sinus or, in very rare cases, of the brain stem. Anhidrosis can be diagnosed in some patients from a history that when they exercise, they perspire on one side of the forehead but not on the other. In other patients, the presence of unilateral anhidrosis can be easily assessed using a metal spoon or similar smooth metal object. Normal perspiration results in fairly smooth skin. A smooth metal object that is passed across the forehead, such the undersurface of a spoon, thus should slide smoothly; however, in a patient with a central or postganglionic Horner syndrome that produces anhidrosis, the spoon will "catch" as it crosses the forehead on the side of the presumed Horner syndrome. Pharmacological testing using several agents can establish 
the diagnosis of a Horner syndrome in most cases and can also be used to localize the lesion (see below).

\section{Pharmacological testing Cocaine}

Cocaine is highly effective in confirming the diagnosis of Horner syndrome. ${ }^{105}$ When there is an interruption to the sympathetic innervation, as occurs in Horner, norepinephrine is not released from the presynaptic nerve endings. Cocaine blocks the reuptake of the norepinephrine that is released from sympathetic nerve endings. This allows norepinephrine to accumulate at the receptors of the effector cells, thus producing dilation of a normal pupil. A Horner pupil, however, is sympathetically denervated and does not respond to the circulating norepinephrine (Figure 5A and B). In a normal eye, a $2 \%-10 \%$ solution of cocaine causes dilation of the pupil. One study noted a mean pupil dilation of $2.14 \mathrm{~mm}$ (range $0.6-4.0 \mathrm{~mm}$ ) in normal eyes in response to a $5 \%$ cocaine solution. ${ }^{48}$ Forty-five minutes after instillation, an anisocoria of at least $0.8 \mathrm{~mm}$ should be considered indicative of Horner syndrome. ${ }^{106}$ However, if the smaller (ie, the suspected Horner) pupil dilates more than $2 \mathrm{~mm}$, even if the post-cocaine anisocoria is greater than $0.8 \mathrm{~mm}$, a Horner syndrome is unlikely. ${ }^{48}$

The challenges with using cocaine are many. Because it is a controlled drug, it can be difficult to obtain and has to be
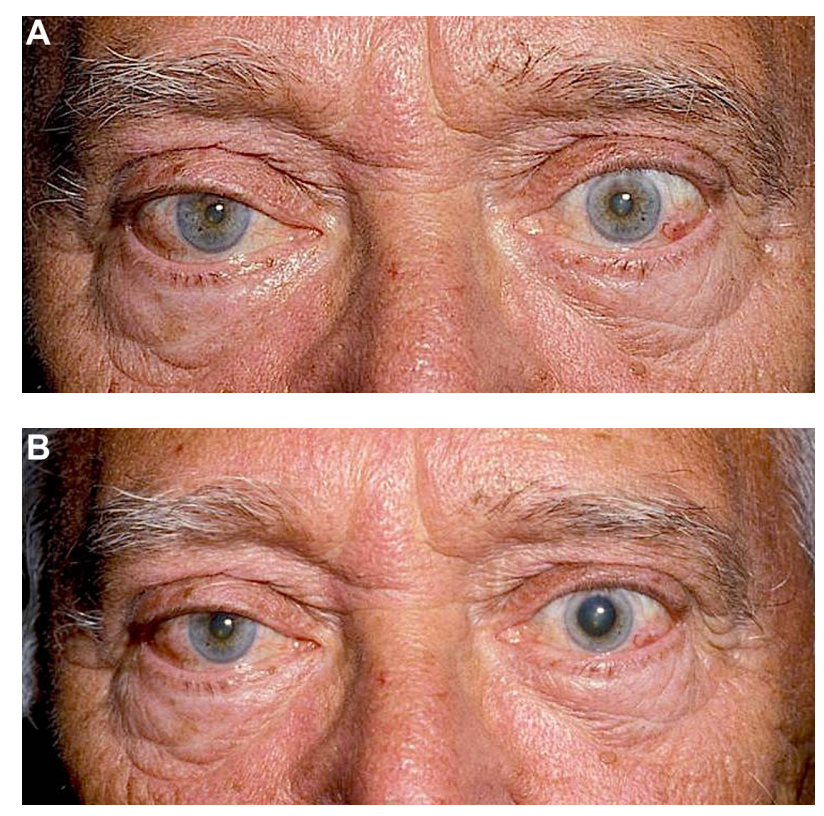

Figure 5 Cocaine Testing for Horner Syndrome.

Notes: (A) Right Horner syndrome in a 72 -year-old man. Note right ptosis and anisocoria with the smaller pupil on the right side. Both pupils reacted briskly to light stimulation. (B) After topical administration of $10 \%$ cocaine drops in both eyes, there is marked dilation of the left pupil but the right pupil dilates only very slightly. This response indicates that the patient has a right Horner syndrome. kept in a secure, locked storage. Some authors also indicate that cocaine has a short shelf-life, although this has not been our experience, with positive responses being elicited despite using cocaine that has been sitting around for several months! On the other hand, metabolites of cocaine are excreted in the urine for up to 2 days after topical administration. This may pose difficulties for patients who have occupations requiring them to undergo random drug screening. One study of 50 patients found positive urine tests for benzoylecgonine (a cocaine metabolite) in $100 \%$ of patients 24 hours after topical administration, in $50 \%$ at 36 hours, and in $2 \%$ after 48 hours. ${ }^{107}$ In addition to these issues, a false-positive response to topical cocaine (ie, lack of dilation in a possible or presumed Horner pupil) can occur in patients who have a miotic pupil associated with severe stromal damage to the iris, neovascularization of the iris, posterior synechiae, or aberrant regeneration of the oculomotor nerve. ${ }^{67}$

\section{Apraclonidine}

Apraclonidine is an alpha-2 adrenergic agonist that is sometimes used to lower intraocular pressure in patients with glaucoma; however, it also has a weak alpha-1 adrenergic effect. Thus, it minimally constricts a normal pupil but dilates a Horner pupil due to denervation supersensitivity of the alpha-1 receptors on its iris dilator muscle, producing a reversal of anisocoria in patients with unilateral Horner syndrome $^{108,109}$ (Figure 6A and B). Koc et al compared 31 patients with Horner syndrome with 54 healthy controls using $0.5 \%$ apraclonidine. ${ }^{110}$ All the Horner pupils had a mean dilation of $2.04 \mathrm{~mm}$ (range $1-4.5 \mathrm{~mm}$ ), whereas the pupils of control eyes had a mean constriction of $0.14 \mathrm{~mm}$ (range $0.5-1 \mathrm{~mm}$ ). Also noted by these investigators was a mean elevation of $1.75 \mathrm{~mm}$ of the upper eyelid on the side of the Horner syndrome compared with $0.61 \mathrm{~mm}$ of elevation in the eyes of the control group. Eyelid elevation, however, is not specific to Horner syndrome alone. ${ }^{110}$

Although apraclonidine has emerged as an excellent alternative to cocaine in the diagnosis of Horner syndrome, several safety concerns have been raised with respect to its use. Watts et al reported three infants under the age of 6 months who became drowsy after topical administration of $1 \%$ apraclonidine. They further described a 10 -week-old infant who received $0.5 \%$ apraclonidine topically in both eyes and was unresponsive for several hours. ${ }^{111}$ Other alphaadrenergic receptor agonists, such as brimonidine, have also been reported to cause bradycardia, somnolence, hypotension, and lethargy in young children. ${ }^{112,113}$ Chen et al reported no side effects with the use of topical $0.5 \%$ apraclonidine in 

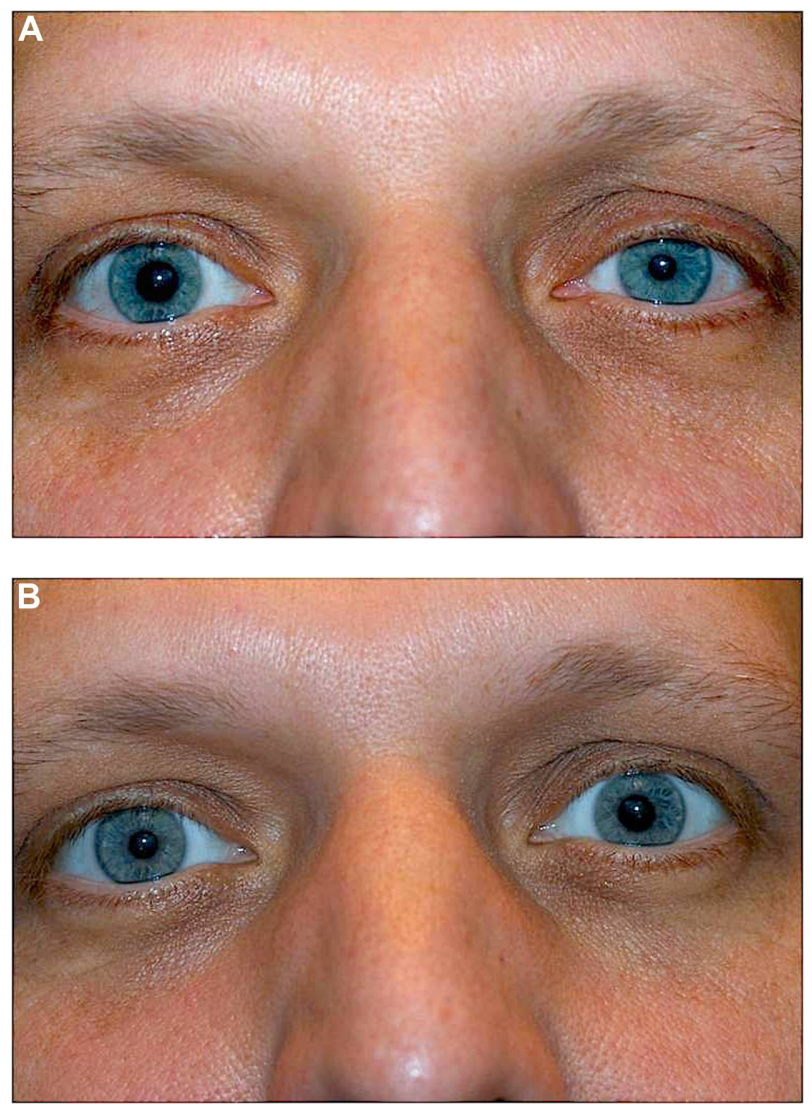

Figure 6 Apraclonidine Testing for Horner Syndrome.

Notes: (A) Left Horner syndrome in a 25 -year-old man. Note left ptosis and anisocoria with the smaller pupil on the left. Both pupils reacted briskly to light stimulation. (B) Forty-five minutes after topical instillation of $1 \%$ apraclonidine in both eyes, there is reversal of anisocoria, with the right pupil now smaller than the left. Note also improvement in the left-sided ptosis.

ten children; ${ }^{114}$ however, none of the patients in this small series were under the age of 6 months. Thus, we agree with others that cocaine is a preferable choice for confirmation of Horner syndrome in infants and young children. ${ }^{82}$

Yet another concern regarding the use of apraclonidine for the diagnosis of Horner syndrome has been the time required for supersensitivity of the iris dilator muscle to develop after interruption of its sympathetic innervation. Upregulation of the postsynaptic receptors may require a certain amount of time after oculosympathetic paresis, and the concern is that a pupil in an acute Horner syndrome will not dilate in this interim phase. ${ }^{115}$ However, Lebas et al described a patient who developed a Horner syndrome as part of a dorsal medullary brainstem infarct, and had a positive apraclonidine test 36 hours after the onset of his symptoms. ${ }^{116}$ Another patient who developed Horner syndrome from a traumatic carotid dissection after a motor vehicle accident had a positive apraclonidine test a mere 3 hours after the onset of his symptoms. ${ }^{117}$ These cases suggest that apraclonidine may, in fact, be effective in the diagnosis of an acute
Horner syndrome. In our opinion, one should use apraclonidine to try to establish a diagnosis in a presumed acute Horner syndrome. If there is a positive response (ie, reversal of anisocoria), this should be taken as indicative of a Horner syndrome. If there is a negative response, the physician must decide if the clinical picture warrants pharmacologic testing with cocaine or further evaluation.

\section{Hydroxyamphetamine}

Whereas both cocaine and apraclonidine are useful in the diagnosis of Horner syndrome, hydroxyamphetamine is useful in distinguishing central and preganglionic lesions from postganglionic ones. ${ }^{118-120}$ Hydroxyamphetamine releases stored norepinephrine from postganglionic adrenergic nerve endings, causing mydriasis in normal pupils. With central and preganglionic lesions, the postganglionic nerve endings are intact. Thus, after topical administration of a $0.5 \%$ solution of hydroxyamphetamine, a Horner pupil will dilate and may even become larger than the contralateral normal pupil. A lesion of the postganglionic sympathetic neurons results in loss of terminal nerve endings and their respective stores of norepinephrine. As such, the affected pupil will not dilate after topical administration of $0.5 \%$ hydroxyamphetamine. ${ }^{121}$ However, as is the case with apraclonidine, false-negative results can occur within a week of damage to the postganglionic neurons, as it takes time for the stores of norepinephrine in the neurons to dissipate. ${ }^{122}$

\section{Phenylephrine}

Some authors believe that a Horner syndrome can be localized not only with hydroxyamphetamine but also with a $1 \%$ solution of phenylephrine or a $2 \%$ solution of epinephrine. ${ }^{123,124}$ These authors suggest that whereas neither a normal pupil nor a central or preganglionic Horner pupil will dilate when either of these solutions is instilled, a postganglionic Horner pupil will dilate after administration of either solution due to acquired adrenergic supersensitivity of the iris dilator muscle. ${ }^{123,124}$ However, it has also been suggested that regardless of the location of the lesion, the Horner pupil will show denervation supersensitivity. ${ }^{125}$ In addition, it must be noted that denervation supersensitivity may take days to weeks to develop. Thus, for these reasons, the test may not provide valid results in either the acute or the chronic setting.

\section{Bilateral Horner syndrome}

A bilateral Horner syndrome can be present in patients with a variety of systemic disorders, including diabetic autonomic neuropathy, amyloidosis, pure autonomic failure, 
Anderson-Fabry disease, familial dysautonomia, and paraneoplastic syndrome. ${ }^{97}$ In a study of 150 patients with generalized autonomic neuropathy, 58 (38.6\%) had evidence of a Horner syndrome. The syndrome was bilateral in 43 (74\%) of these individuals. ${ }^{126}$

\section{Differential diagnosis}

Unilateral ptosis and miosis associated with normal pupillary constriction can have other etiologies. Physiological anisocoria occurs in up to $20 \%$ of the normal population, and some of these patients might have unilateral ptosis ipsilateral to the smaller pupil due to dehiscence of the levator tendon or other causes. ${ }^{127}$ Other causes of anisocoria, such as a tonic pupil, Argyll Robertson pupils, pharmacologic pupillary blockade, oculomotor nerve palsy, ocular surgery, and iris atrophy following inflammation or trauma should not be confused with a Horner syndrome as such pupils do not constrict or constrict very slowly to light stimulation. In addition to dehiscence of the levator tendon, unilateral ptosis can be caused by other neurologic, myopathic, mechanical, and neuromuscular conditions.

\section{Evaluation}

Once the diagnosis of a Horner syndrome has been confirmed, an appropriate evaluation should be performed. As noted above, in infants and children, this should involve a complete physical examination, magnetic resonance imaging of the brain, neck, and chest, and an assay for urinary catecholamines. ${ }^{82}$ In adults with an acquired Horner syndrome, a simple $\mathrm{x}$-ray of the neck in flexion and extension can identify cervical spondylosis, a common cause of both central and preganglionic Horner syndromes. In addition, magnetic resonance imaging of the brain with contrast should reveal many other causes of a central or postganglionic Horner syndrome, including brainstem infarct, intracranial tumor, and demyelinating disease, whereas computed tomographic scanning of the chest can reveal tumors and other lesions of the lungs and thorax responsible for preganglionic Horner syndromes. In addition, computed tomography or magnetic resonance angiography can effectively evaluate the neck vasculature to rule out dissections and other lesions of the ipsilateral internal carotid artery that may cause both preganglionic and postganglionic Horner syndromes, largely obviating the need for invasive catheter angiography. ${ }^{128,129}$

Davagnanam et al have provided an algorithm to determine which patients with Horner syndrome should undergo urgent imaging. ${ }^{130}$ They have suggested that a patient with Horner syndrome with no history of trauma, no pain, and no localizing signs, does not require urgent imaging but instead can undergo non-urgent imaging performed within 6 weeks with clinical reassessment. Nonetheless, it should be noted that such patients may still have potentially life-threatening underlying pathology. ${ }^{131,132}$

\section{Conclusion}

The etiologies of Horner syndrome are numerous, with some being life-threatening. Thus, the physician who diagnoses a possible Horner syndrome must carefully assess the patient for other neurologic manifestations that may help confirm the diagnosis and be helpful in localizing the site of injury. In addition to a complete physical examination, pharmacological testing is a valuable tool that can aid not only with the diagnosis but also the localization of a Horner syndrome, so as to direct further testing and management of the patient.

\section{Disclosure}

The authors report no conflicts of interest in this work.

\section{References}

1. Kisch B. Horner's syndrome, an American discovery. Bull Hist Med. 1951;25:284-288.

2. Mitchell SW, Morehouse GR, Keen WW. Gunshot Wounds and Other Injuries of the Nerves. Philadelphia, PA, USA: Lippincott; 1964.

3. Horner JF. On a form of ptosis. Klin Monatsbl Augenheilkd. 1969;7: 193-198.

4. Stone WM, de Toledo J, Romanul FC. Horner's syndrome due to hypothalamic infarction: clinical, radiologic and pathologic correlations Arch Neurol. 1986,43:199-200.

5. Austin CP, Lessell S. Horner's syndrome from hypothalamic infarction. Arch Neurol. 1991;48:332-334.

6. Rosetti AO, Reichhart MD, Bogousslavsky J. Central Horner's syndrome with contralateral ataxic hemiparesis: a diencephalic alternate syndrome. Neurology. 2003;61:334-338.

7. Nagy AN, Hayman LA, Diaz-Marchan PJ, Lee AG. Horner's syndrome due to first-order neuron lesions of the oculosympathetic pathway. AJR Am J Roentgenol. 1997;169:581-584.

8. Coppeto JR. Superior oblique paresis and contralateral Horner's syndrome. Ann Ophthalmol. 1983;15:681-683.

9. Guy JR, Day AL, Mickle JP, Schatz NJ. Contralateral trochlear nerve paresis and ipsilateral Horner's syndrome. Am J Ophthalmol. 1989;107: 73-76.

10. Müri RM, Baumgartner RW. Horner's syndrome and contralateral trochlear nerve palsy. Neuroophthalmology. 1995;15:161-163.

11. Kellen RI, Burde RM, Hodges FJ 3rd, Roper-Hall G. Central bilateral sixth nerve palsy associated with a unilateral preganglionic Horner's syndrome. J Clin Neuroophthalmol. 1988;8:179-184.

12. Sacco RL, Freddo L, Bello JA, Odel JG, Onesti ST, Mohr JP. Wallenberg's lateral medullary syndrome: clinical-magnetic resonance imaging correlations. Arch Neurol. 1993;50:609-614.

13. Fisher CM, Tapia J. Lateral medullary infarction extending to the lower pons. J Neurol Neurosurg Psychiatry. 1987;50:620-624.

14. Kim JS. Pure lateral medullary infarction: clinical-radiological correlation of 130 acute, consecutive patients. Brain. 2003;126:1864-1872.

15. Smith DB, Demasters BK. Demyelinative disease presenting as Wallenberg's syndrome: report of a patient. Stroke. 1981;12:877-878.

16. Pomerantz H. Isolated Horner syndrome and syrinx of the cervical spinal cord. Am J Ophthalmol. 2002;133:702-704. 
17. Kobayashi N, AsamotoS, Doi H, Sugiyama H. Brown-Sequard syndrome produced by cervical disc herniation: report of two cases and review of the literature. Spine J. 2003;6:530-533.

18. Kramer W, van der Does de Willebois JJ. Occlusion of the anterior spinal artery in the cervical cord with sympathetic spasm of the pupil on finger movement. Folia Psychiatr Neurol. 1959;62:458-464.

19. Furukawa T, Toyokura Y. Alternating Horner syndrome. Arch Neurol. 1974;30:311-313

20. Tan E, Kansu T, Saygi S, Zileli T. Alternating Horner's syndrome: a case report and review of the literature. Neuroophthalmology. 1990;10: $19-22$.

21. Maloney WF, Younge BR, Moyer NJ. Evaluation of the causes and accuracy of pharmacologic localization in Horner's syndrome. Am J Ophthalmol. 1980;90:394-402.

22. Thompson H, Maxner C, Corbett J. Horner's syndrome due to damage to the preganglionic neuron of the oculosympathetic pathway. In: Huber A, editor. Symphathetics and the Eye [English Translation]. Stuttgart, Germany: Ferdinand Enke; 1990.

23. Kovacic S, Lovrencic-Huzjan A, Drpa D, Hat J, Belina S. Horner's syndrome as an initial sign of metastatic breast cancer: case report. Cancer Detect Prev. 2007;31:450-452.

24. Arcasoy SM, Jett JR. Superior pulmonary sulcus tumors and Pancoast's syndrome. N Engl J Med. 1997;337:1370-1376.

25. Hilaris BS, Martini N, Wong GY, et al. Treatment of superior sulcus tumor (Pancoast tumor). Surg Clin North Am. 1987;67:965-977.

26. Ohta Y, Toda A, Ohta N, et al. An atypical lung carcinoid tumor resected after induction therapy with involvement of the superior sulcus region: report of a case. Surg Today. 2002;32:632-634.

27. Hatton MQ, Allen MB, Cooke NJ. Pancoast syndrome: an unusual presentation of adenoid cystic carcinoma. Eur Respir J. 1993;6: 271-272.

28. Chong KM, Hennox SC, Sheppard MN. Primary hemangiopericytoma presenting as a Pancoast tumor. Ann Thorac Surg. 1993;55:9.

29. Herbut PA, Watson JS. Tumor of the thoracic inlet producing the Pancoast syndrome: a report of seventeen cases and a review of the literature. Arch Pathol (Chic). 1946;42:88-103.

30. Chen KT, Padmanabhan A. Pancoast syndrome caused by extramedullary plasmacytoma. J Surg Oncol. 1983;24:117-118.

31. Mills PR, Han LY, Dick R, Clarke SW. Pancoast syndrome caused by a high grade B cell lymphoma. Thorax. 1994;49:92-93.

32. Dolan G, Smith J, Reilly JT. Extrapulmonary lymphomatoid granulomatosis presenting as Pancoast's syndrome. Postgrad Med J. 1991;67:914-915.

33. Rabano A, La Scala M, Hernandez P, Barros JL Thyroid carcinoma presenting as Pancoast's syndrome. Thorax. 1991;46:270-271.

34. Vandenplas O, Mercenier C, Trigaux JP, Delaunois L. Pancoast's syndrome due to Pseudomonas aeruginosa infection of the lung apex. Thorax. 1991;46:683H-684H.

35. Gallagher KJ, Jeffrey RR, Kerr SM, Steven MM. Pancoast syndrome: an unusual complication of pulmonary infection by Staphylococcus aureus. Ann Thorac Surg. 1992;53:903-904.

36. Vamos G, Papp A. [Pancoast syndrome and lung tuberculosis]. Schweiz Z Tuberk. 1960;17:423-430. German.

37. Simpson FG, Morgan M, Cooke NJ. Pancoast's syndrome associated with invasive aspergillosis. Thorax. 1986;41:156-157.

38. Mitchell DH, Sorrell TC. Pancoast's syndrome due to pulmonary infection with Cryptococcus neoformans variety gattii. Clin Infect Dis. 1992;14:1142-1144.

39. Hood RJ, Jensen ME, Reibel JF, Levine PA. Schwannoma of the cervical sympathetic chain. Ann Otol Rhinol Laryngol. 2000;109:48-51.

40. Karaman E, Isildak H, Ylimaz M, et al. Management of paragangliomas in otolaryngology practice: review of a 7 -year experience. J Craniofac Surg. 2009;20:1294-1297.

41. Jindal T, Chaudhary R, Sharma N, Meena M, Dutta R, Kumar A. Primary mediastinal chondrosarcoma with Horner's syndrome. Gen Thorac Cardiovasc Surg. 2011;59:145-147.
42. Gedde SJ, Clark FJ, Johns JA, Johns KJ. Horner's syndrome as a complication of pacemaker insertion. Am J Ophthalmol. 1991;112:97-99.

43. Barbut D, Gold JP, Heinemann MH, Hinton RB, Trifiletti RR. Horner's syndrome after coronary artery bypass surgery. Neurology. 1996; 19:181-184.

44. Schachner SM, Reynolds AC. Horner syndrome during lumbar epidural analgesia for obstetrics. Obstet Gynecol. 1982;59:31S.

45. Jeret JS, Mazurek AA. Acute postpartum Horner's syndrome due to epidural anesthesia. Arch Ophthalmol. 1995;113:560.

46. Davis P, Watson D. Horner's syndrome and vocal cord paralysis as a complication of percutaneous internal jugular vein catheterisation in adults. Anaesthesia. 1982;37:587-588.

47. Gasch AT. Horner's syndrome secondary to chest tube placement. Ann Ophthalmol. 1996;28:235-239.

48. Wilhelm H, Ochsner H, Kopycziok E, Trauzettel-Klosinski S, Schiefer U, Zrenner E. Horner's syndrome: a retrospective analysis of 90 cases and recommendations for clinical handling. Ger J Ophthalmol. 1992;1: 96-102.

49. Parkinson D, Johnston J, Chaudhuri A. Sympathetic connections of the fifth and sixth cranial nerves. Anat Rec. 1978;191:221-226.

50. Parkinson D. Further observations on the sympathetic pathways to the pupil. Anat Rec. 1988;220:108-109.

51. Anson J, Crowell RM. Cervicocranial arterial dissection. Neurosurgery. 1991;29:89-96.

52. Mokri B, Sundt TM Jr, Houser OW, Piepgras DG. Spontaneous dissection of the cervical internal carotid artery. Ann Neurol. 1986;19: 126-138.

53. Lee WW, Jensen ER. Bilateral internal carotid dissection due to trivial trauma. J Emerg Med. 2000;19:35-41.

54. Biousse V, Touboul P-J, D’Anglejan-Chatillon J, Lévy C, Schaison M, Bousser MG. Ophthalmologic manifestations of internal carotid artery dissection. Am J Ophthalmol. 1998;126:565-577.

55. Monteiro ML, Coppeto JR. Horner's syndrome associated with carotid artery atherosclerosis. Am J Ophthalmol. 1988;105:93-94.

56. Cengiz K, Aykin A, Diren B. Intrathoracic goiter with hyperthyroidism, tracheal compression, superior vena cava syndrome and Horner's syndrome. Chest. 1990;87:1005-1006.

57. Inci S, Bertan V, Kansu T, Cila A. Horner's syndrome due to jugular venous ectasia. Childs Nerv Syst. 1995;11:533-535.

58. Keane JR. Oculosympathetic paresis: analysis of 100 hospitalized patients. Arch Neurol. 1979;36:13-16.

59. Liu GT, Deskin RW, Bienfang DC. Horner's syndrome caused by intra-oral trauma. J Clin Neuroophthalmol. 1992;12:110-115.

60. Worthington JP, Snape L. Horner's syndrome secondary to a basilar skull fracture after maxillofacial trauma. J Oral Maxillofac Surg. 1998;56:996-1000.

61. Striph GG, Burde RM. Abducens nerve palsy and Horner's syndrome revisited. J Clin Neuroophthalmol. 1988;8:13-17.

62. Smith EF, Santamarina L, Wolintz AH. Herpes zoster ophthalmicus as a cause of Horner syndrome. J Clin Neuroophthalmol. 1993;13: 250-253.

63. Myles WM, Maxner CE. Localizing value of concurrent sixth nerve paresis and postganglionic Horner's syndrome. Can J Ophthalmol. 1994;29:39-42.

64. Kurihara T. Abducens nerve palsy and ipsilateral incomplete Horner syndrome: a significant sign of locating the lesion in the posterior cavernous sinus. Intern Med. 2006;45:993-994.

65. Tsuda H, Ishikawa H, Asayama K, Saito T, Endo S, Mizutani T. Abducens nerve palsy and Horner syndrome due to metastatic tumor in the cavernous sinus. Intern Med. 2005;44:644-646.

66. Riley FC, Moyer NJ. Oculosympathetic paresis associated with cluster headaches. Am J Ophthalmol. 1971;72:763-768.

67. Martin T. Horner's syndrome, pseudo-Horner's syndrome, and simple anisocoria. Curr Neurol Neurosci Rep. 2007;7:397-406.

68. Grimson BS, Thompson HS. Raeder's syndrome: a clinical review. Surv Ophthalmol. 1980;24:199-210. 
69. Salvesen R. Raeder's syndrome. Cephalalgia. 1999;19S:42-45.

70. Goadsby PJ. Raeder's syndrome: paratrigeminal paralysis of the oculopupillary sympathetic system. J Neurol Neurosurg Psychiatry. 2002;72:297-299.

71. Jeffery AR, Ellis FJ, Repka MX, Buncic JR. Pediatric Horner syndrome. JAAPOS. 1998;2:159-167.

72. Weinstein JM, Zweifel TJ, Thompson HS. Congenital Horner's syndrome. Arch Ophthalmol. 1980;98:1074-1078.

73. Sayed AK, Miller BA, Lack EE, Sallan SE, Levey RH. Heterochromia iridis and Horner's syndrome due to paravertebral neurilemmoma. J Surg Oncol. 1983;22:15-16.

74. Borzyskowski M, Harris RF, Jones RW. The congenital varicella syndrome. Eur J Pediatr. 1981;137:335-338.

75. Bayatpour M, Logan J, Perry HP, Finley M. Horner's syndrome due to congenital cytomegalovirus infection. South Med J. 1982;75: 220-221.

76. Reader AL 3rd, Massey EW. Fibromuscular dysplasia of the carotid artery: a cause of congenital Horner's syndrome? Ann Ophthalmol. 1980;12:326-330.

77. Woodruff G, Buncic JR, Morin JD. Horner's syndrome in children. J Pediatr Ophthalmol Strabis. 1988;25:40-44.

78. Bernstein ML, Leclerc JM, Bunin G, et al. A population-based study of neuroblastoma incidence, survival and mortality in North America. J Clin Oncol. 1992;10:323-329.

79. Woods WG, Gao R-N, Shuster JJ, et al. Screening of infants and mortality due to neuroblastoma. $N$ Engl J Med. 2002;346:1041-1046.

80. Nitschke R, Smith EI, Shochat S, et al. Localized neuroblastoma treated by surgery - a Pediatric Oncology Group study. J Clin Oncol. 1988;6:127-129.

81. Nitschke R, Smith EI, Altshuler G, et al. Postoperative treatment of non-metastatic visible residual neuroblastoma - a Pediatric Oncology Group study. J Clin Oncol. 1991;9:1181-1188.

82. Mahoney NR, Liu GT, Menacker SJ, Wilson MC, Hogarty MD, Maris JM. Pediatric Horner syndrome: etiologies and roles of imaging and urine studies to detect neuroblastoma and other responsible mass lesions. $\mathrm{Am}$ J Ophthalmol. 2006;142:651-659.

83. George ND, Gonzalez G, Hoyt CS. Does Horner's syndrome in infancy require investigation? Br J Ophthalmol. 1998;82:51-54.

84. Smith SJ, Diehl N, Leavitt JA, Mohney BG. Incidence of pediatric Horner syndrome and risk of neuroblastoma: a population based study. Arch Ophthalmol. 2010;128:324-329.

85. Anderson RL, Beard C. The levator aponeurosis. Attachments and their clinical significance. Arch Ophthalmol. 1977;95:1437-1441.

86. Kakizaki H, Malhotra R, Selva D. Upper eyelid anatomy: an update. Ann Plast Surg. 2009;63:336-343.

87. Carraway JH. Surgical anatomy of the eyelids. Clin Plast Surg. 1987;14: 693-701.

88. Bang YH, Park SH, Kim JH, Cho JH, Lee CJ, Roh TS. The role of Muller's muscle reconsidered. Plast Reconstr Surg. 1998;101:1200-1204.

89. Beard C. Muller's superior tarsal muscle: anatomy, physiology, and clinical significance. Ann Plast Surg. 1985;14:324-333.

90. Lepore FE. Enophthalmos and Horner's syndrome. Arch Neurol. 1983;50:460.

91. Van der Wiel HL, Van Gijn J. No enophthalmos in Horner's syndrome. J Neurol Neurosurg Psychiatry. 1987;50:498.

92. Nielsen PJ. Upside-down ptosis in patients with Horner's syndrome. Acta Ophthalmol. 1983;61:952-957.

93. Pilley S, Thompson H. Pupillary "dilatation lag" in Horner's syndrome. Br J Ophthalmol. 1975;59:731-735.

94. Van der Wiel HL, Van Gijn J. Horner's syndrome: criteria for oculo-sympathetic denervation. J Neurol Sci. 1982;56:293-298.

95. Verdick R, Thompson HS. Infrared videography of the eyes. J Ophthalmic Photogr. 1991;13:19-21.

96. Krzizok T, Graf M, Kraus S. [Photo- and videographic determination of the dilatation deficit in differential diagnosis of Horner syndrome]. Ophthalmologe, 1995;92:125-131. German [with English abstract].
97. Smith SA, Smith SE. Bilateral Horner's syndrome: detection and occurrence. J Neurol Neurosurg Psychiatry. 1999;66:48-51.

98. Crippa SV, Borruat FX, Kawasaki A. Pupillary dilation lag is intermittently present in patients with a stable oculosympathetic defect (Horner syndrome). Am J Ophthalmol. 2007;143:712-715.

99. Diesenhouse MC, Palay DA, Newman NJ, To K, Albert DM. Acquired heterochromia with Horner syndrome in two adults. Ophthalmology. 1992;99:1815-1817.

100. Cogan DG. Accommodation and the autonomic nervous system. Arch Ophthalmol. 1937;18:739-766.

101. Cobb S, Scarlett HW. A report of eleven cases of cervical sympathetic nerve injury causing the oculopupillary syndrome. Arch Neurol Psychiatry. 1920;3:636-654.

102. Thompson HS. The pupil. In: Adler's Physiology of the Eye. 9th ed. St Louis, MO, USA: Mosby-Year Book; 1992.

103. Smith G, Dyches TJ, Burden RM. Topographic analysis of Horner's syndrome. Otolaryngol Head Neck Surg. 1986;94:451-457.

104. Romano A, Kurchin A, Rudich R, Adar R. Ocular manifestations after upper dorsal sympathectomy. Ann Ophthalmol. 1979;11: $1083-1086$.

105. Thompson HS. Diagnosing Horner's syndrome. Trans Am Acad Ophthalmol Otolaryngol. 1977;83:840-842.

106. Kardon RH, Denison CE, Brown CK, Thompson HS. Critical evaluation of the cocaine test in the diagnosis of Horner's syndrome. Arch Ophthalmol. 1990;108:384-387.

107. Jacobson DM, Berg R, Grinstead GF, Kruse JR. Duration of positive urine for cocaine metabolite after ophthalmic administration: implications for testing patients with suspected Horner's syndrome using ophthalmic cocaine. Am J Ophthalmol. 2001;131:742-747.

108. Morales J, Brown SM, Abdul-Rahim AS, Crosson CE. Ocular effects of apraclonidine in Horner syndrome. Arch Ophthalmol. 2000;118: 951-954.

109. Brown SM, Aouchiche R, Freedman KA. The utility of $0.5 \%$ apraclonidine in the diagnosis of Horner syndrome. Arch Ophthalmol. 2003;121:1201-1203.

110. Koc F, Kavuncu S, Kansu T, Acaroglu G, Firat E. The sensitivity and specificity of $0.5 \%$ apraclonidine in the diagnosis of oculosympathetic paresis. Br J Ophthalmol. 2005;89:1442-1444.

111. Watts P, Satterfuekd D, Lim MK. Adverse effects of apraclonidine used in the diagnosis of Horner syndrome in infants. J AAPOS. 2007;11: 282-283.

112. Enyedi LB, Freedman SF. Safety and efficacy of brimonidine in children with glaucoma. J JAAPOS. 2001;5:281-284.

113. Carlson J, Zabriskie N, Known T, Barbe ME, Scott WE. Apparent central nervous system depression in infants after the use of topical brimonidine. Am J Ophthalmol. 1999;128:255-256.

114. Chen PL, Chen JT, Lu DW, et al. Comparing efficacies of $0.5 \%$ apraclonidine with $4 \%$ cocaine in the diagnosis of Horner's syndrome in pediatric patients. J Ocul Pharmacol Ther. 2006;22:182-187.

115. Kardon R. Are we ready to replace cocaine with apraclonidine in the pharmacologic diagnosis of Horner syndrome? J Neuroophthalmol. 2005;25:69-70.

116. Lebas M, Seror J, Debroucker T. Positive apraclonidine test 36 hours after acute onset of Horner syndrome in dorsolateral pontomedullary stroke. J Neuroophthalmol. 2010;30:12-17.

117. Cooper-Knock J, Pepper I, Hodgson T. Early diagnosis of Horner syndrome using topical apraclonidine. J Neuroophthalmol. 2011;31: 214-216.

118. Thompson HS, Mensher JH. Adrenergic mydriasis in Horner's syndrome: hydroxyamphetamine test for diagnosis of postganglionic defects. Am J Ophthalmol. 1971;72:472-480.

119. Cremer SA, Thompson HS, Digre KB, Kardon RH. Hydroxyamphetamine mydriasis in Horner's syndrome. Am J Ophthalmol. 1990;110: $71-76$.

120. Thompson HS, Mensher JH. Hydroxyamphetamine test in Horner's syndrome. Am J Ophthalmol. 1975;79:523-526. 
121. Cremer SA, Thompson HS, Digre KB, Kardon RH. Hydroxyamphetamine mydriasis in normal subjects. Am J Ophthalmol. 1990;110: 66-70.

122. Donahue SP, Lavin PJ, Digre K. False-negative hydroxyamphetamine (Paredrine) test in acute Horner's syndrome. Am J Ophthalmol. 1996;122:900-901.

123. Ramsay DA. Dilute solutions of phenylephrine and pilocarpine in the diagnosis of disordered autonomic innervation of the iris. Observations in normal subjects, and in the syndromes of Horner and Holmes-Adie. J Neurol Sci. 1986;73:125-134.

124. Danesh-Meyer HV, Savino P, Sergott R. The correlation of phenylephrine $1 \%$ with hydroxyamphetamine $1 \%$ in Horner syndrome. $\mathrm{Br} J$ Ophthalmol. 2004;88:592-593.

125. Smit DP. Pharmacologic testing in Horner's syndrome - a new paradigm. S Afr Med J. 2010;100:738-740.

126. Bremner F, Smith S. Pupil findings in a consecutive series of 150 patients with generalized autonomic neuropathy. $J$ Neurol Neurosurg Psychiatry. 2006;77:1163-1168.

127. Ettinger ER, Wyatt HJ, London R. Anisocoria: variation and clinical observation with different conditions of illumination and accommodation. Invest Ophthalmol Vis Sci. 1991;32:501-509.
128. Levy C, Laissy JP, Raveau V, et al. Carotid and vertebral artery dissections: three dimensional time-of flight MR angiography and MR imaging versus conventional angiography. Radiology. 1994;190:97-103.

129. Leclerc X, Godefroy O, Salhi A, Lucas C, Leys D, Pruvo JP. Helical $\mathrm{CT}$ for the diagnosis of extra-cranial internal carotid artery dissection. Stroke. 1996;27:461-466.

130. Davagnanam I, Fraser CI, Miszkiel K, Daniel CS, Plant GT. Adult Horner's syndrome: a combined clinical, pharmacological, and imaging algorithm. Eye (London). 2013;27:271-298.

131. Lee SYS, Mollan S, Senthil L, et al. Aetiology and Investigation of Adult Acquired Horner Syndrome. Presented at the United Kingdom Neuro-ophthalmology Special Interest Group, Glasgow, Scotland, March 13, 2013

132. Al-Moosa A, Eggenberger E. Neuroimaging yield in isolated Horner syndrome. Curr Opin Ophthalmol. 2011;22:268-271.

133. Glaser JS. editor, Neuro-ophthalmology. 1st ed. Hagerstown MD, USA: Harper \& Row; 1978.

134. Kardon R. Anatomy and physiology of the autonomic nervous system. In: Miller NR, Biousse V, Kerrison JB, editors. Walsh and Hoyt's Clinical Neuro-Ophthalmology. 6th ed. Baltimore, MD, USA: LippincottWilliams \& Wilkins; 2005:649-714.
Eye and Brain

\section{Publish your work in this journal}

Eye and Brain is an international, peer-reviewed, open access journal focusing on clinical and experimental research in the field of neuroophthalmology. All aspects of patient care are addressed within the journal as well as basic research. Papers covering original research, basic science, clinical and epidemiological studies, reviews and evaluations,

\footnotetext{
Submit your manuscript here: http://www.dovepress.com/eye-and-brain-journal
}

\section{Dovepress}

guidelines, expert opinion and commentary, case reports and extended reports are welcome. The manuscript management system is completely online and includes a very quick and fair peer-review system, which is all easy to use. Visit http://www.dovepress.com/testimonials.php to read real quotes from published authors. 